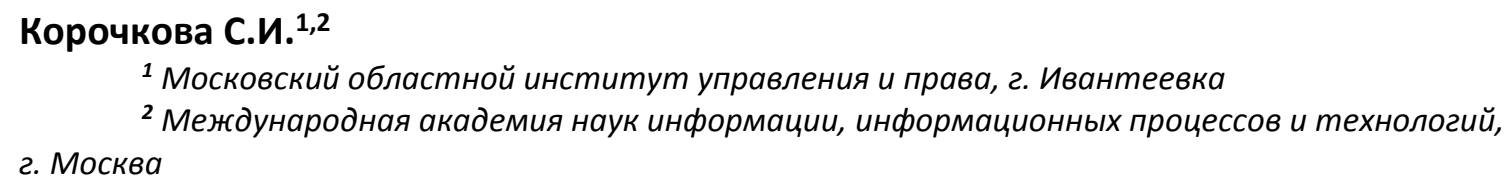

\title{
Интеграционные процессы в наукоемких организациях в рамках стратегических альянсов
}

\begin{abstract}
АННОТАЦИЯ:
В статье рассматриваются проблемы наукоемких организаций и возможности их развития в рамках стратегических альянсов. Стратегический альянс объединяет несколько независимых предприятий, поэтому интеграционные процессы в подобных организациях могут помочь привлечь дополнительное финансирование и разделить риски. Методологической основой этого процесса является теория управления бизнеспроцессами, позволяющая обеспечить оптимальность и рациональность цепочки создания ценности для потребителя агропромышленной продукции, выравнивая возможности участников интегрированного формирования. Целью альянсов является дать возможность организациям чувствовать себя более уверенно в рамках договорных отношений, при этом не лишать каждое предприятие юридической самостоятельности. Основной проблемой для машиностроения является низкий уровень научных разработок, что $и$ решается путем объединения организаций в альянсы и осуществлению господдержки. Для отечественного машиностроения наибольший интерес представляют псевдоконцентрационные альянсы, которые способствуют внедрению научнотехнических разработок и развитию производства.

КЛЮЧЕВЫЕ СЛОВА: стратегический альянс, наукоемкие организации, интеграционные процессы, конкуренция, глобализация, эффрективность альянсов
\end{abstract}

\section{JEL: D74, F61, L62}

ДЛЯ ЦИТИРОВАНИЯ:

Корочкова С.И. Интеграционные процессы в наукоемких организациях в рамках стратегических альянсов // Экономика, предпринимательство и право. - 2015. - Т. 5. № 2. - c. 59-72. - doi: 10.18334/epp.5.2.421

Корочкова Светлана Ивановна, канд. экон. наук, профессор, директор Московского представительства Московского областного института управления и права, г. Ивантеевка; членкорреспондент Международная академия наук информации, информационных процессов и технологий, г. Москва (sveta.corochkov@yandex.ru)

ПОСТУПИЛО В РЕДАКЦИЮ: 15.06.2015 / ОПУБЛИКОВАНО: 30.06.2015 ОТКРЫТЫЙ ДОСТУП: doi: 10.18334/epp.5.2.421

(с) Корочкова С.И. / Публикация: ООО Издательство "Креативная экономика"

Статья распространяется по лицензии Creative Commons CC BY-NC-ND (http://creativecommons.org/licenses/by-nc-nd/3.0/)

ЯЗЫК ПУБЛИКАЦИИ: русский 
Важной особенностью наукоемких предприятий являются большие риски деятельности, поэтому интеграционные процессы в подобных организациях могут помочь привлечь дополнительное финансирование и разделить риски. К категории наукоемкой в настоящее время обычно относят такую продукцию, при производстве которой доля затрат на науку в общей сумме издержек или сумме продаж составляет не менее 2,5\% [5]. Часто просто субподрядные отношения между производителем и поставщиком не дают возможности для развития продукции и проведения совместных исследований, так как невозможно осуществить процессы взаимного обучения и обмена опытом и организации ведут себя скорее как соперники, а не как партнеры. Альянсы дают возможность организациям чувствовать себя более уверенно в рамках договорных отношений, но в то же время не лишают каждое предприятие юридической самостоятельности. Существует несколько типов альянсов, которые условно можно разделить на альянсы между фирмамиконкурентами и не конкурентами [4]. Далее будет проанализирован каждый тип альянса с точки зрения предоставления им возможности наилучшего развития предприятиям, производящим наукоемкую продукцию.

На сегодняшний день не существует четкого определения понятию «стратегический альянс». Суть данного понятия отражает следующее определение: «стратегический альянс» - это объединение нескольких независимых предприятий, которые намерены заняться каким-либо производством или осуществить новый проект при отсутствии всех условий для подобной деятельности в одной организации. К альянсам между фирмами не конкурентами относятся следующие типы - транснациональные совместные предприятия, вертикальные соглашения о партнерстве и межотраслевые соглашения [1].

Транснациональные совместные предприятия - объединение организаций с целью расширения рынка сбыта и укрепления за счет нового партнера на новом развивающемся рынке [1]. На практике транснациональные компании решают следующие задачи: создание подобных объединений дает возможность местной организации выйти за рамки отношений «поставщик-клиент», которыми характеризуется большинство взаимодействий при передаче технологий; ограничение возможности маневрирования транснациональной компании путем участия в процессе принятия решений местных организаций; 
интеграция страны или региона в мировую экономику. Снижение издержек и достижение эффекта синергии в данном случае достигается путем открытия совместного филиала, причем процентным соотношением между держателями акций, рекомендуемым на практике, является примерно 25\% транснационального предприятия к 75\% акций у местной организации. Помимо этого, у партнера могут быть активы такого рода (недвижимость, инфраструктура, сеть реализации продукции и т.д.), которые можно использовать в рамках совместного предприятия и которые было бы намного труднее обеспечить даже в самых благоприятных условиях. Например, местные организации лучше знают наиболее благоприятные варианты размещения производственных или складских помещений. В машиностроительной отрасли существует много отечественных предприятий, нуждающихся в помощи или реорганизации, поэтому сотрудничество с транснациональной компанией в долгосрочной перспективе может уменьшить возможности отечественным предприятиям.

Следующий тип альянса - вертикальное партнерство, предполагающее объединение поставщиков и производителей, возникло в автомобильной промышленности, однако, на практике довольно часто это приводит к тому, что производитель попадает в зависимость к поставщику [1]. Кроме того, прибыль в данном альянсе дает эффект масштаба, поэтому, при гибком и единичном производстве жесткая структура может тормозить развитие производства в целом и совершенствование продукции. Вертикальный альянс изменяет отношения между поставщиками и производителями, позволяя совместно разрабатывать продукт, намного повышая качество. Таким образом, зависимость производителя от поставщика не исчезает, но приобретает новый характер - отношения становятся более прозрачными и доверительными, однако, не следует забывать, что в долгосрочной перспективе данный вид альянсов уменьшает отраслевую конкуренцию и ведет к «устареванию» технологий.

Последний вариант объединения фирм не конкурентов межотраслевые соглашения, создающиеся с целью взаимопомощи и рассматривающие взаимное сотрудничество в качестве приоритетного направления своих производственных программ. Данные общества не ставят своей целью налагать финансовые обязательства на своих партнеров, а согласовывают производственные программы и делят риски. Часто в юридическом отношении это является неформальными 
соглашениями о взаимной поддержки, а также долевым участием в капитале партнера. В большинстве случаев межотраслевые соглашения заключаются с целью открытия нового вида производственной деятельности и образования нового конкурентного пространства.

Интеграционные альянсы являются достаточно перспективными для отрасли машиностроения, так как способствуют осуществлению научного прорыва, внедрению новых технологий силами нескольких организаций при условии поддержки со стороны государства. Кроме того, интеграционные альянсы способствуют реализации протекционистской политике внутри государства. Особенностью данного альянса является то, что обычно срок его действия ограничивается периодом реализации совместного проекта. Общими усилиями компании разрабатывают новый или совершенствуют имеющийся продукт, обогащая собственные производственные возможности и пополняя количество научно-технических разработок. Но в долгосрочной перспективе организации чаще всего становятся друг для друга конкурентами, поэтому в процессе совместной деятельности возникает проблема защиты научных разработок отдельных организаций в составе альянса.

Для предприятий отрасли машиностроения данный тип альянса может позволить осуществить прорыв в производственной сфере, а также внедрить научную разработку. Еще одним вариантом альянса фирм конкурентов является псевдоконцентрационный альянс, позволяющий достигнуть эффект масштаба без слияния предприятий, а также использовать преимущества концентрации, при этом не осуществляя программы концентрации не деле, то есть, не доходя до полного слияния компаний на деле. При реализации соглашений в рамках псевдоконцентрационного альянса возникает проблема распределения обязанностей с целью избежания дублирования производственных процессов [3]. Для этого необходим обмен знаниями в организациях, что чревато возможными утечками информации, но, принимая во внимание, что речь идет о псевдоконцентрационном альянсе, который, как правило, является долгосрочным и обмен технологиями неизбежен, целесообразно организовать центр знаний и совместных разработок и стимулировать каждую из организаций к обмену опытом. Еще одним следствием совместной деятельности в течение длительного периода времени является постепенная специализация организаций-участников альянса, которая в конечном счете ограничивает развитие отдельной 
компании. Но в целом, данные альянсы являются достаточно стабильными в долгосрочной перспективе и позволяют совместными усилиями осуществить множество успешных проектов.

Последним типом альянса между фирмами-конкурентами являются комплементарные альянсы, основанные на взаимном дополнении производственных функций [1]. При создании альянса подобного типа вклад каждого партнерского предприятия в программу сотрудничества носит взаимодополняющий характер и существенно отличается от вклада другого партнера. Как правило, один из партнеров предоставляет альянсу свою продукцию, тогда как другой партнер - сеть реализации продукции. В контексте глобализации рынков при установлении партнерских отношений необходимо учитывать подобные интересы партнеров. То есть, при создании комплементарного альянса компания может заручиться поддержкой коммерческих подразделений непосредственного конкурента и проникнуть в новые географические зоны мира. В машиностроении комплементарный альянс может помочь фирме-производителю расширить географию рынка. Однако, в комплементарных альянсах партнерское предприятие, способствующее вхождению продуктов своего партнера на свой рынок сбыта, даже если при этом удается решить какие-либо насущные проблемы, не должно упускать из виду, что оно помогает своему партнеру стать в тот или иной момент одним из непосредственных конкурентов. Этим и объясняется осторожность, с которой на практике образуются альянсы подобного типа. Таким образом, для отечественного машиностроения наибольший интерес представляют псевдоконцентрационные альянсы, которые способствуют внедрению научно-технических разработок и развитию производства. Вообще, существует несколько причин создания подобных альянсов: обеспечение взаимной поддержки. Подобные соглашения могут быть полезны при обеспечении взаимной поддержки со стороны участников альянса, а также для расширения рынка сбыта и совершенствования технологий. 


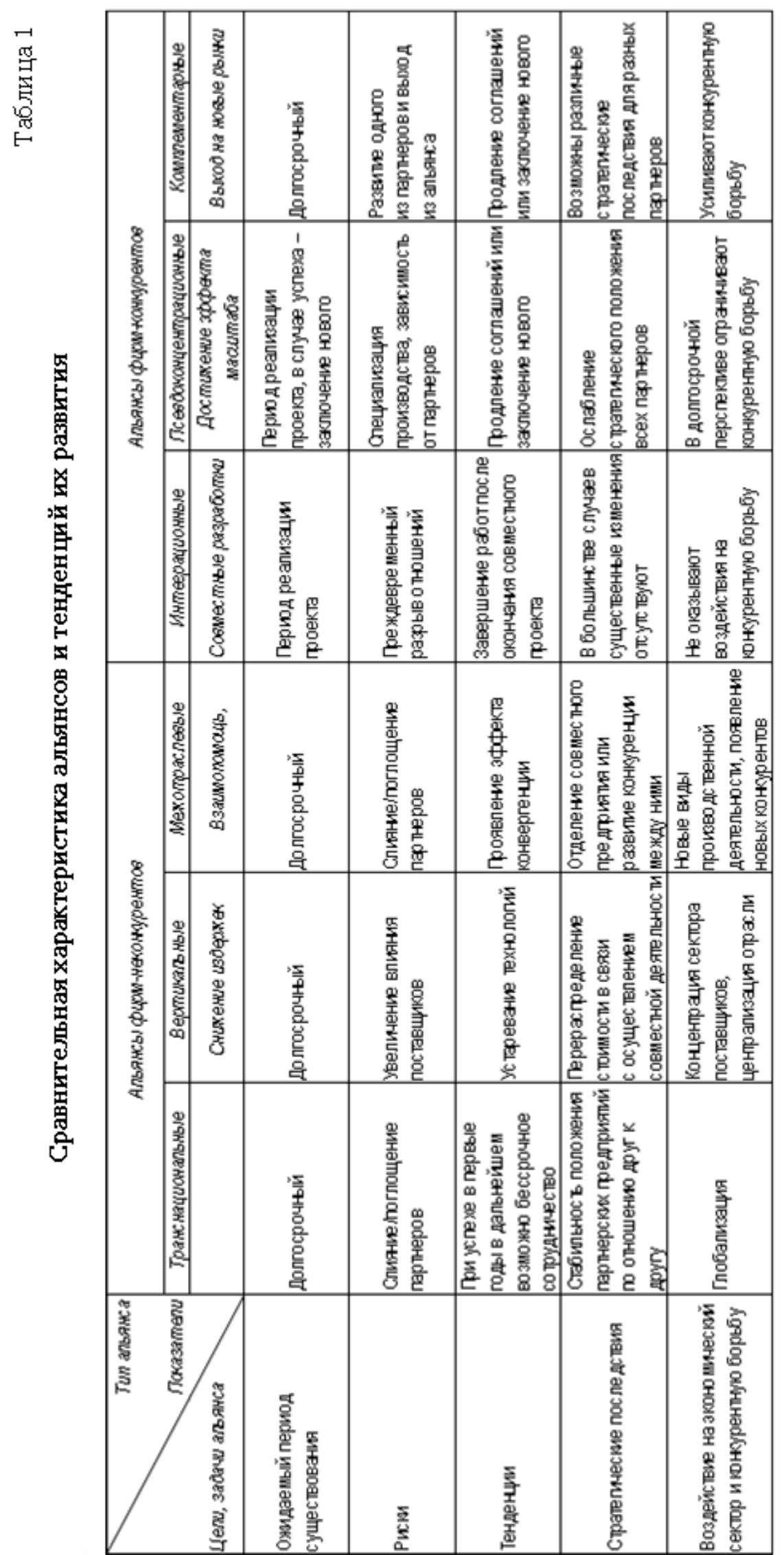


Одной из значительных проблем, с которыми сталкиваются организации внутри альянса, является возрастающая со временем зависимость от других членов альянса, поэтому еще до вступления организаций в альянс, необходимо продумать последствия такого решения и предусмотреть вероятность наступления событий, которые могут привести к разрыву отношений внутри альянса и выходу организации, хотя для межотраслевых альянсов как раз характерен долгосрочный период существования. Поэтому, принимая во внимание особенности отрасли, можно с большой степенью вероятности говорить о благоприятных перспективах существования псевдоконцентрационных альянсов. На рисунке 1 изображены конкурентные преимущества отрасли, определяемые ресурсным потенциалом и количественнокачественным уровнем факторов машиностроительной отрасли. Методологической основой этого процесса является теория управления бизнес-процессами, позволяющая обеспечить оптимальность и рациональность цепочки создания ценности для потребителя агропромышленной продукции, выравнивая возможности участников интегрированного формирования. Основной проблемой для машиностроения является низкий уровень научных разработок, что и решается путем объединения организаций в альянсы и осуществлению господдержки.

Устойчивость стратегического альянса и эффективность его деятельности определяются максимизацией синергетического эффекта от взаимодополнения внутренних возможностей участников альянса и состоянием бизнес-климата как совокупности внешних факторов, формирующих условия его функционирования, среди которых в силу специфики аграрного производства, доминирующую роль выполняют органы государственной власти региона. Кроме того, при анализе эффективности имеющихся связей следует учитывать уровень расходов на координацию совместной деятельности. Согласно реляционной теории, степень координации различных компаний в процессе создания совместной организационной структуры может намного превысить необходимый для минимизации издержек уровень [4]. Это объясняется тем, что компании готовы понести дополнительные и даже существенные расходы на координационную структуру, поскольку их основная цель - обеспечить устойчивость конъюнктурных экономических факторов. В реальных ситуациях поведение компании на рынке определяется не только теоретическими выкладками о жесткой 
конкуренции и противостоянии, устанавливая связь с разными партнерами из частного и общественного сектора, создавая альянсы компании пытаются «организовать рынок» в целях избегания опасных ситуаций. Таким образом, в некоторых ситуациях компании встают на «соглашательскую» позицию: вместо того, чтобы максимизировать прибыль и минимизировать издержки, они пытаются изыскать «удовлетворительные» с экономической точки зрения решения, которые позволили бы им в существенной мере сократить уровень неопределенности и риска на рынке. То есть, реляционная составляющая играет столь же важную роль при решении об объединении организаций в альянсы, как и конкурентная. Перечень основных типов альянсов с их основными характеристиками приведен в таблице 1.

Еще одной проблемой наукоемких организаций является наращивание и эффективное использование научно-технического потенциала организации, поэтому данные организации более других заинтересованы в развитие отношений с ВУЗами, проф.тех. училищами и другими структурами среднего и высшего профессионального образования [3]. Подобное сотрудничество может помочь при решении стратегических проблем модернизации и развития наукоемких отраслей. То есть, на данном этапе экономического развития актуально стратегическое взаимодействие сфер профессионального образования и бизнеса в рамках стратегического партнерства. Таким образом, стратегическое партнерство следует рассматривать как основную и наиболее перспективную форму интеграционного взаимодействия учреждений профессиональной школы и предприятий.

На данный момент, анализируя вопросы качества высшего профессионального образования (ВПО) очевидно, что главными являются следующие противоречия между достигнутыми возможностями ВПО и требованиями, предъявляемыми к нему реальным сектором экономики и обществом в целом:

- разрыв между уровнем знаний и прикладными умениями, компетенциями выпускников образовательных учреждений;

- несоответствие спектра направлений подготовки специалистов происходящим структурным изменениям народного хозяйства и отдельных отраслей; 


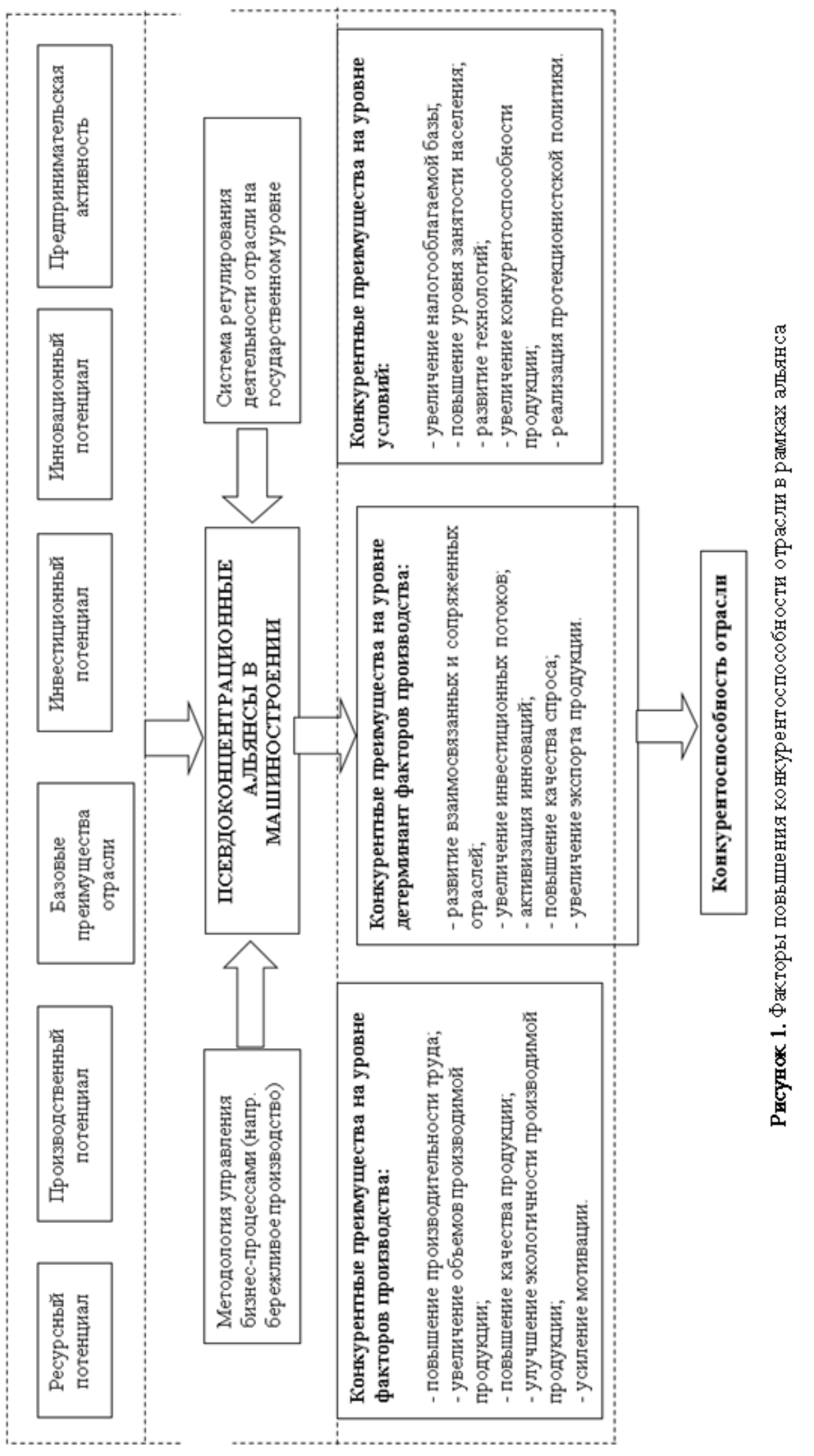


- трудности в адаптации молодых специалистов к производственной среде, отсутствие эффективного закрепления их на рабочих местах;

- низкая конкурентоспособность выпускников вуза, не имеющих практического опыта решения профессиональных задач или не знакомых со спецификой конкретного производства. Здесь перспективным направлением представляется их системное взаимодействие на основе интегрированных проектов [2].

Для устранения указанных противоречий существуют следующие наиболее распространенные разновидности целевой подготовки кадров [5]:

1. Целевая контрактная подготовка (целевой прием в вуз) повышение доступности профессионального образования для учеников сельских и отдаленных школ;

2. Специализация подготовки кадров - введение специализаций путем включения регионального и вузовских компонентов учебных планов, недостатком которой указывается отсутствие «обратной связи», взаимодействия промышленности и образования;

3. Филиалы кафедр на предприятиях, задачами которых обычно является практическое решение следующих проблем:

- ускоренная адаптация выпускников вуза к условиям предприятия и решению научно-практических задач по его профилю;

- вовлечение студентов в научно-исследовательскую деятельность по тематике предприятия на основе развития методик учебно-исследовательских работ студентов в условиях НИИ;

- социальная адаптация и интеграция студентов как личностей в корпоративную культуру и производственную среду предприятия;

- закрепление кадров - выпускников вуза на предприятии;

- вовлечение преподавателей в решение научно-технических проблем предприятия, в выполнение хоздоговорных работ;

- вовлечение специалистов предприятия в научную деятельность по востребованным в производстве темам под руководством ведущих ученых вуза и в педагогическую работу, развитие профессиональных качеств;

- активизация довузовской подготовки абитуриентов к поступлению и обучению их в вузе с целью формирования схемы 
непрерывного профессионального образования по цепочке: «школа- вуз - филиал кафедры - предприятие».

Кроме того, одним из основных принципов разнообразия и развития в развивающихся системах является межотраслевой подход, реализовать который в ВУЗе не сложно, организовав междисциплинарные промышленно-образовательные структуры, интегрирующие усилия нескольких кафедр университета и высокотехнологичных предприятий.

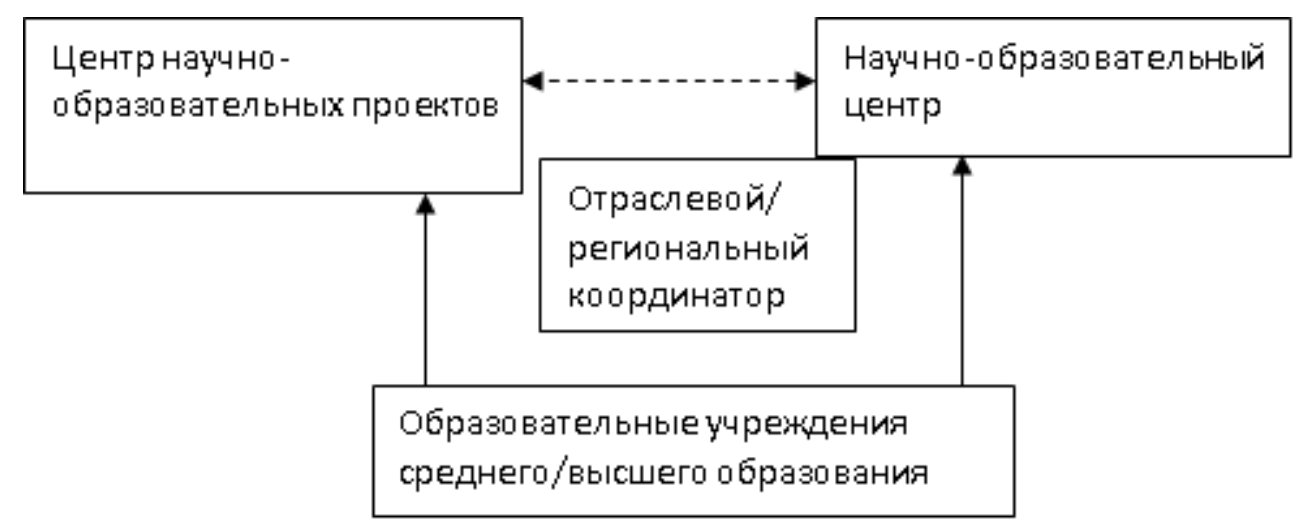

Рисунок 2. Схема производственно-образовательных альянсов

Организационную схему межотраслевых комплексов целесообразно построить путем развития взаимодействия существующих структур регионального или отраслевого управления (рисунок 2). Управление производстенно-образовательным комплексом целесообразно осуществить на основе единого подхода к его компонентам как социально-экономическим системам. Научное и учебно-методическое руководство могут выполнить инновационные университетские центры или межуниверситетские учреждения. С точки зрения организационно-правовой формы взаимодействия данные альянсы являются консорциумами. Таким образом, на данный момент можно сказать, что развитый и апробированный подход на основе междисциплинарных проектных промышленно-образовательных комплексов является эффективным дополнением к существующим видам взаимодействия реального сектора экономики, с одной стороны, и высшего и дополнительного профессионального образования, с другой стороны.

Подводя итог, можно сказать, что предприятия наукоемких отраслей в современном мире сталкиваются с возрастающими 
требованиями к качеству, сроками и внешнему виду продукции, к более прозрачному и эффективному ведению бизнеса и т.д. Поэтому проведен анализ возможных вариантов деятельности наукоемких организаций в рамках альянса. На примере машиностроительной отрасли рассматривались наиболее подходящие типы альянса. На основании отраслевых тенденций был выделен псевдоконцентрационный альянс как наиболее отвечающий особенностям отрасли и требованиям, предъявляемым к наукоемким организациям. Среди существующих типов организационной формы взаимодействия, соответствующих понятию «альянс», был выделен консорциум, концерн, а также совместные предприятия, как наиболее целесообразные для решения задач, поставленных перед наукоемкими предприятиями. Проблему несоответствия между направлениями обучающих программ ВУЗов и реалиям практической деятельности возможности решить или существенно уменьшить в рамках производственно-образовательных альянсов, как формы эффективного взаимодействия профессионального образования и бизнеса.

ИсточникИ:

1. Гаретт Б., Дюссож П. Стратегические альянсы. - М.: ИНФА-М, 2011. - С. 50-104.

2. Гринберг Р.С. О промышленном развитии Российской Федерации / Р.С. Гринберг, Д.Е. Сорокин // Экономика и управление. - 2010. - №5. С. 2-7.

3. Ларина Ю.С. Стратегические альянсы как типичный пример стратегической сети // Российское предпринимательство. - 2013. - № 7 (229). - с. 91-99.

4. Лунькин А.Н. Становление и развитие многоуровневых стратегических альянсов среднего профессионального образования на основе общественногосударственно-частного партнерства // Модернизация среднего профессионального образования на инновационной основе. - М.: ЦентрЛитНефтеГаз, 2011. - С. 47- 63.

5. Стратегические альянсы. - М.: Альпина Бизнес Букс, 2010 г. - С. 19-26.

6. Уоллес Р. Л. Стратегические альянсы в бизнесе. Технологии построения долгосрочных партнерских отношений и создание совместных предприятий. - М.: Добрая книга, 2009 г. - С. 32-37.

7. Федорова Л.А. Устойчивость развития наукоемких компаний как ключевой фактор обеспечения национальной безопасности России // Креативная экономика. 2014. - № 3 (87). - c. 75-79. 
Svetlana I. Korochkova, Candidate of Science, Economy, Professor, Director of the Moscow representative office of Moscow Regional Institute of Management and Right; Corresponding member of International Academy of Information, Information processes and Technology, Moscow

\title{
Integration processes in high technology organizations within the framework of strategic alliances
}

\begin{abstract}
This article discusses the high technology organizations and development opportunities within the framework of strategic alliances. Strategic alliance unites a few independent enterprises, therefore integration processes in similar organizations can help to attract refinancing and divide risks. Methodological basis of this process is a theory of management of businessprocesses, allowing to provide an optimality and rationality of chainlet of creation of value for the user of agroindustrial products, even possibilities of participants of the computerintegrated forming. The purpose of alliances is to enable organizations to feel more confidently within the framework of contractual relations, here not to deprive every enterprise of legal independence. A basic problem for an engineer is a low level of scientific developments, what decides by the association of organizations in alliances and to realization of national support. For a domestic engineer most interest is presented by pseudoconcentration alliances which are instrumental in introduction of scientific and technical developments and development of production.

KEYWORDS: strategic alliance, high technology organization, integration processes, competition, globalization, the effectiveness of alliances
\end{abstract}


